\title{
Study on preterm pre mature rupture of membrane with special reference to maternal and its fetal outcome
}

\author{
Shadma Khan ${ }^{1}$, Aymen Ahmad Khan ${ }^{2} *$
}

\author{
${ }^{1}$ Department of Obstetrics and Gynecology, Katihar Medical College, Bihar, India \\ ${ }^{2}$ Department of General Surgery, Integral Institute of Medical Sciences and Research, Lucknow, Uttar Pradesh, India
}

Received: 19 June 2016

Accepted: 09 July 2016

\section{*Correspondence:}

Dr. Aymen Ahmad Khan,

E-mail: aymenahmadkhan@gmail.com

Copyright: ( $)$ the author(s), publisher and licensee Medip Academy. This is an open-access article distributed under the terms of the Creative Commons Attribution Non-Commercial License, which permits unrestricted non-commercial use, distribution, and reproduction in any medium, provided the original work is properly cited.

\begin{abstract}
Background: To study see maternal and fetal outcome in preterm pre mature rupture of membrane. To reach consciousness how early PPROM cases could be terminated with least morbidity to the mother and fetus

Methods: The study conducted in Department of Obstetrics and Gynecology, Katihar Medical College and Hospital, Bihar between November 2013 to august 2015. Sixty Pregnant mothers attended and admitted through antenatal clinic OPD and Emergency with complaining PPROM

Result: Over all age range of mothers was (18 to 38) years and over. Over all mean of parity of mothers was $0.87 \pm 1.2$ birth .The Morbidity exceeded to 46 (76.67\%) when the duration of PROM was more than 24 hours. As the Duration of PROM was 12-24 hrs and more the effect on consequences had been disastrous on new born. Mean of weight at birth was $1730.0 \pm 516.5 \mathrm{gm}$ and Median (Min-Max.) weight was (1000 - 3000) gm. There was $100 \%$ morbidity and mortality in gestational age group of 24- 26 weeks in mothers while as gestational age increases the morbidly and mortality decreases. The morbidity and mortality of newly born babies was maximum in cord compression followed by very low birth weight.

Conclusions: Preterm prelabour of the fetal membranes contributes to one-third of all preterm births. Conservative management to prolong gestation should be performed in the absence of evidence of infection. There is currently no evidence regarding the risks and benefits of prolongation of gestation beyond 34 weeks gestation.
\end{abstract}

Keywords: Premature rupture of the membrane, Maternal and neonatal outcome, Risk factors

\section{INTRODUCTION}

Premature rupture of membranes (PROM) is defined as rupture of fetal membranes before onset of labour. If it happens between 37 completed weeks and 42 weeks of gestational age, it is called term premature rupture of membranes (TPROM), while that occurring between 24 weeks and 37 weeks is called preterm premature rupture of membranes (PPROM). Rupture of membranes for $>24$ hours before delivery is called prolonged rupture of membranes.
Fetal membranes are made of an outer four to six layered chorion attached to a collagen rich connective tissue and an inner single cell layer amnion. ${ }^{1}$ Weakness in the chorioamnion membrane is the overall mechanism of PROM, which may be due to deficiency of type III collagen, reduced size of the membrane at the affected site and reduced collagen content. ${ }^{1-4}$ In addition, it may be caused by proteolytic enzymes from bacteria. ${ }^{6}$

A number of risk factors e.g. smoking have been identified to be directly associated with PPROM. However, the cause is uncertain and it is believed to be multifactorial. ${ }^{7}$ 
Patients with premature rupture of membranes may present with leakage of vaginal fluid or vaginal bleeding but without contractions. If infection sets in, patients may also present with symptoms and signs of chorioamnionitis. Diagnosis of PPROM is made through history from the woman and by a sterile speculum vaginal examination. Pooling of liquor in the posterior vaginal fornix or leakage of it from the cervical os confirms the diagnosis. Ferning of liquor as observed on the microscope or change of nitrazine paper to blue because of the alkalinity of the amniotic fluid is supportive of the diagnosis of premature rupture of membranes.

In PPROM, the management involves administration of antibiotics that reduces the risk of perinatal infection and increases the latency period while steroids reduce perinatal morbidity and mortality. 2,9

Preterm premature rupture of membranes is one of the significant causes of preterm delivery and is associated worldwide with increased rates of neonatal and maternal morbidity and Mortality. ${ }^{7,10}$

AIMS of the study was to study maternal outcome in reference to chorioamnionitis in relation to period of gestation prior to delivery and after delivery and to study fetal outcome like perinatal mortality and morbidity (special emphasis on birth weight, maturity, neonatal sepsis and respiratory distress syndrome) and to reach consciousness how early PPROM cases could be terminated with least morbidity to the mother and fetus.

\section{METHODS}

\section{Study area}

Department of Obstetrics and Gynecology, Katihar Medical College and Hospital, Katihar, Bihar.

\section{Study population}

Pregnant mothers attended and admitted through antenatal clinic OPD and Emergency with complaining PPROM. Patients presented with PPROM and also have associated multiple gestations, congenital malformation with polyhydramnios, APH and transverse lie are excluded from this study.

Study period: November 2013 To August 2015.

Sample size: 60

\section{Parameters to be studied}

- $\quad$ Fetal outcome like perinatal mortality and morbidity (special emphasis on birth weight, maturity, neonatal sepsis and respiratory distress syndrome): By clinical examination and monitoring and blood culture.
- Maternal outcome in reference to chorioamnionitis in relation to period of gestation prior to delivery and after delivery: By clinical and microbiological examination

- To reach consciousness how early PPROM cases could be terminated with least morbidity to the mother and fetus: By critically analysis of all parameters.

\section{Study tools}

Pregnant mothers attending antenatal clinic OPD or Emergency with PPROM were assessed, evaluated clinically. Investigation of obstetrical significance like $\mathrm{Hb} \%$, VDRL, HIV, HbSAg, PPBS, blood grouping and typing, routine urine examination and routine sonography were done.

\section{Diagnosis of PPROM}

History: Gush of watery fluid.

\section{Examination:}

Inspection: Examination done in the labour room under strict aseptic precaution in lithotomy position. After proper antiseptic dressing with strict aseptic precaution, posterior vaginal speculum was inserted to press down the post vaginal wall. Anterior wall retractor was used to retract anterior wall. Amniotic fluid was found to present in the vault. If no fluid is present, patient was asked to cough, slight pressure on the uterus may also serve the same purpose. Fluid for laboratory test was collected over lower blade of the speculum before it comes into contact with vaginal wall.

Nitrazine test: $\mathrm{Ph}$ of draining fluid was determined with the help of nitrazine paper and it was between 7 to 7.5 in all cases.

Internal Examination: To detect the presence or absence of lower membranes and whenever any cord prolapse was looked for. All doubtful cases excluded from this study

\section{Clinical Examination}

A through meticulous clinical examination as described in the proforma was done for each of the patients.

\section{Study of Liquor Amnii}

In all cases of PPROM liquor amnii was collected as intra-cervical swab, high vaginal swab with strict aseptic precaution for culture sensitivity test where $\mathrm{C} / \mathrm{S}$ was done liquor amnii was collected by amniocentesis just before making uterus incision. The sample was cultured aerobically and anaerobically for detection of any pathogenic organisms. 


\section{Monitoring labour and puerperium}

Patients were monitored clinically whenever they go into labour. Condition of mother, condition of fetus and progress of labour observed meticulously with details recorded .Elective of emergency $\mathrm{C} / \mathrm{S}$, low forceps application done whenever necessary. Condition of baby at birth were observed and recorded. Maternal condition and complications if any after delivery up to discharge were observed.

\section{Study of new born infant}

The study of new born infant were done according to proforma. Investigation done after birth where throat swab and blood culture for presence of any organisms.

\section{Statistical analysis}

All the results were expressed in mean \pm SD or frequency (percentage). Statistical analysis was done by SPSS software 20 version. $\mathrm{p}<0.05$ was considered as significant.

\section{RESULTS}

Twenty seven $(45 \%)$ patients were below 24 years of age, $24(40 \%)$ were in the age group of 25-30 years, and 9 $(15 \%)$ patients were in the age range of above 31 years. A total number of 60 patients were inducted for study whose over all age range was (18 to 38 ) years and over all mean age of patients was $25.73 \pm 5.1$ years.

Thirty (50\%) women were pregnant for only once, 27 (45\%) women were pregnant 2 to -4 times, and remaining $3(5 \%)$ were pregnant for over 5 times. The mean frequency of pregnancy was $(1.87-1.2)$ and over all range of pregnancy was (1 to 6) times.

While $30(50 \%)$ pregnant women under study have had zero Parity, 17 (28.33\%) women had only 1 parity, 12 $(20 \%)$ had 2 to 4 parity and remaining 1 pregnant woman had a parity level of over 5 birth. Over all mean of parity was $0.87 \pm 1.2$ birth and parity range was ( 0 to5) birth.

While $8(13.3 \%)$ women have had a gestational age of 22 to 28 weeks, $41(68.3 \%)$ were in the gestational age category of 28-34 weeks and remaining 11 (18.3\%) were in the gestational age of over 34 weeks. Over all mean of parity was $0.87 \pm 1.2$ birth and parity range was (0 to- 5$)$ birth.

The various parameters like onset and duration of discharge and its smell, temperature of patient, abdominal tenderness and fetal heart rate etc. on presentation for clinical evaluation.

$12(20 \%)$ women have had an indication of labour in the past, $4(6.67 \%)$ have had Preterm PROM, $1(1.67 \%)$ cases were of obstructed labour in the past, $8(13.33 \%)$ had previous history of PROM, $13(21.67 \%)$ have had Cesarean deliveries in the past, $4(6.67 \%)$ were the cases of Preterm labour, $10(16.67 \%)$ were patients of Miscarriage in the past, and $7(11.67 \%)$ chose Elective abortion. Risk factors for PPROM; Symptoms and signs of chorioamnionitis after admission.

$7(11.67 \%)$ women had a White blood cell count of $>11$ $\mathrm{x} 910 / \mathrm{L}$, and $9(15 \%)$ women had a cell count of $<11 \mathrm{x}$ 910/L. In case of 44 (73.33) patients however, White blood cell count was not carried out.

Table 1: Various parameters on presentation for clinical evaluation.

\begin{tabular}{|c|c|c|c|}
\hline Variable & & $\begin{array}{l}\text { Frequency } \\
(\%)\end{array}$ & $95 \% \mathrm{Cl}$ \\
\hline \multirow{3}{*}{$\begin{array}{l}\text { Hours of } \\
\text { draining } \\
\text { from onset to } \\
\text { presentation }\end{array}$} & $\begin{array}{l}<24 \\
\text { hours }\end{array}$ & 37 (61.67) & $\begin{array}{l}49.02 \text { to } \\
72.91\end{array}$ \\
\hline & $\begin{array}{l}24-48 \\
\text { hours }\end{array}$ & $12(20)$ & $\begin{array}{l}11.83 \text { to } \\
31.78\end{array}$ \\
\hline & $\begin{array}{l}>48 \\
\text { hours }\end{array}$ & $11(18.33)$ & $\begin{array}{l}10.56 \text { to } \\
29.92\end{array}$ \\
\hline \multirow[t]{2}{*}{ Draining smell } & Yes & $9(15)$ & $\begin{array}{l}8.1 \text { to } \\
26.11\end{array}$ \\
\hline & No & $51(85)$ & $\begin{array}{l}73.89 \text { to } \\
95.19\end{array}$ \\
\hline \multirow[t]{2}{*}{$\begin{array}{l}\text { Temperature on } \\
\text { admission }\end{array}$} & $>380 \mathrm{C}$ & $2(3.33)$ & $\begin{array}{l}0.92 \text { to } \\
11.36\end{array}$ \\
\hline & $<380 \mathrm{C}$ & $58(96.67)$ & $\begin{array}{l}88.64 \text { to } \\
99.08\end{array}$ \\
\hline \multirow{2}{*}{$\begin{array}{l}\text { Abdominal } \\
\text { Tenderness } \\
\text { on Admission }\end{array}$} & Yes & $3(5)$ & $\begin{array}{l}1.71 \text { to } \\
1.37\end{array}$ \\
\hline & No & $57(95)$ & $\begin{array}{l}86.3 \text { to } \\
98.29\end{array}$ \\
\hline \multirow[t]{4}{*}{$\begin{array}{l}\text { FHR on } \\
\text { admission }\end{array}$} & $<120$ & $1(1.67)$ & $\begin{array}{l}0.3 \text { to } \\
10.14\end{array}$ \\
\hline & $\begin{array}{l}120 \text { to } \\
160\end{array}$ & $54(90)$ & $\begin{array}{l}79.85 \text { to } \\
95.34\end{array}$ \\
\hline & $>160$ & $1(1.67)$ & $\begin{array}{l}0.3 \text { to } \\
10.14\end{array}$ \\
\hline & $\begin{array}{l}\text { Not } \\
\text { done }\end{array}$ & $4(6.67)$ & $\begin{array}{l}2.62 \text { to } \\
15.93\end{array}$ \\
\hline
\end{tabular}

Table 2: Risk factors for PPROM.

\begin{tabular}{|lll|}
\hline Risk factor & Frequency $(\%)$ & $95 \%$ CI \\
\hline Anemia & $13(21.67)$ & 13.13 to 33.62 \\
\hline $\begin{array}{l}\text { Urinary tract } \\
\text { infections }\end{array}$ & $8(15)$ & 6.91 to 24.16 \\
\hline $\begin{array}{l}\text { Lower genital } \\
\text { tract infection }\end{array}$ & $7(11.67)$ & 5.77 to 22.18 \\
\hline Cervical stich & $1(1.67)$ & 0.3 to 10.14 \\
\hline Malpresentations & $4(6.67)$ & 2.62 to 15.93 \\
\hline Hydramnias & $2(3.33)$ & 0.92 to 11.36 \\
\hline No risk factors & $24(40)$ & 28.57 to 52.63 \\
\hline
\end{tabular}


Table 3: Symptoms and signs of chorioamnionitis after admission.

\begin{tabular}{|lll|}
\hline $\begin{array}{l}\text { Symptoms and signs of } \\
\text { chorioamnionitis after } \\
\text { admission }\end{array}$ & No $(\%)$ & $\begin{array}{l}95 \% \\
\text { CI }\end{array}$ \\
\hline Maternal fever & $5(8.33)$ & $\begin{array}{l}3.61 \text { to } \\
18.06\end{array}$ \\
\hline Maternal tachycardia & $1(1.67)$ & $\begin{array}{l}0.3 \text { to } \\
10.14\end{array}$ \\
\hline Foul smelling discharge & $1(1.67)$ & 0.3 to \\
& & 10.14 \\
\hline None & $53(88.33)$ \\
\hline
\end{tabular}

When the duration of PROM was $<12$ hrs there were only $2(3.33 \%)$ cases of maternal morbidity, which have risen to $12(20 \%)$ cases when the Duration of PROM had gone up to $12-24 \mathrm{hrs}$. Morbidity figures have further exceeded to $46(76.67 \%$ ) when the duration of PROM was more than 24 hours.

When the Duration of PROM had been $<12$ hrs the consequences had not been that disastrous as and when the Duration of PROM was 12-24 hrs and still more.
Table 4: Mode of delivery.

\begin{tabular}{|lll|}
\hline Mode of Delivery & Frequency $(\%)$ & $95 \%$ CI \\
\hline Vaginal vertex & $17(28.33)$ & $\begin{array}{l}18.5 \text { to } \\
28.33\end{array}$ \\
\hline Vaginal assisted & $18(30)$ & 19.9 to \\
breech delivery & & 42.51 \\
\hline Instrumental & $4(6.67)$ & 2.62 to \\
& & 15.93 \\
\hline Caesarean section & $21(35)$ & 24.17 to \\
& & 47.64 \\
\hline
\end{tabular}

In $19(31.67 \%)$ cases weight of newly born babies was found to be only 1000-1499 gm. In another 37 (61.67\%) cases weight at birth was 1500-2499 gm. It was only in 4 $(6.67 \%)$ cases weight at the time of birth was recorded to be $>2500 \mathrm{gm}$.Mean of weight at birth was 1730.0 $\pm 516.5 \mathrm{gm}$. and Median (Min-Max.) weight was (1000 - 3000) gm.

Table 5: Distribution of morbidity and mortality based on gestational age.

\begin{tabular}{|lllll|}
\hline $\begin{array}{l}\text { Gestational age (in } \\
\text { Week) }\end{array}$ & Frequency $(\%)$ & Morbidity $(\%)$ & Mortality $(\%)$ & Total $(\%)$ \\
\hline $24-26$ & $3(5 \%)$ & $2(66.67 \%)$ & $1(33.335)$ & $3(100 \%)$ \\
\hline $27-29$ & $5(8.33 \%)$ & $2(40.0 \%)$ & $2(40 \%)$ & $4(80 \%)$ \\
\hline $30-32$ & $20(33.33 \%)$ & $7(35 \%)$ & $3(15 \%)$ & $10(50 \%)$ \\
\hline $33-36$ & $32(53.33 \%)$ & $4(12.5 \%)$ & $7(21.88 \%)$ & $11(34.38 \%)$ \\
\hline Total & $60(100 \%)$ & $15(25 \%)$ & $13(21.67)$ & $28(46.67 \%)$ \\
\hline
\end{tabular}

Table 6: Morbidity and mortality of newly born babies.

\begin{tabular}{|ll|}
\hline Causes & Frequency $(\%)$ \\
\hline Very low birth weight & $5(17.9 \%)$ \\
\hline Fetal distress & $4(14.3 \%)$ \\
\hline Cord Compression & $6(21.4 \%)$ \\
\hline Necrotizing enterocolitis & $2(7.14 \%)$ \\
\hline Hypoxia & $3(10.7 \%)$ \\
\hline Sepsis & $8(28.5 \%)$ \\
\hline Total & $28(100 \%)$ \\
\hline
\end{tabular}

While babies born from $14(23.33 \%)$ women had an Apgar score (5 mins) between 0-5, babies from 13 (21.67) women were assessed for an Apgar score (5 mins) of 5-7 and babies from 33 (55\%) women were adjudged for an Apgar score (5 mins) of 7-10.

In case of $3(5 \%)$ women with a lower gestational age of 24-26 weeks, the morbidity was $2(66.67 \%)$ \&mortality was1 (33.335) percent . Thus morbidity and mortality was $100 \%$. In case of $5(8.33 \%)$ cases whose gestational age was slightly better $27-29$ weeks morbidity was $2(40.0 \%)$ and mortality was $2(40 \%)$ percent. Under this category total morbidity and mortality was $4(80 \%)$. Further in case of $20(33.33 \%)$ women having gestational age 30-32 week the morbidity was $7(35 \%)$ and mortality was 3 (15\%) percent making a total morbidity and mortality combined $10(50 \%)$. In the last category of $32(53.33 \%)$ women having a normal gestational age of 33-36 weeks morbidity and mortalitywere 4 (12.5\%) and 7 (21.88\%) respectively, making a total of morbidity and mortality 11 (34.38\%).Over all morbidity was 15 (25\%) and mortality figures were 13 (21.67). While very low birth weight had been the cause of morbidity and mortality for babies born to $5(17.9 \%)$ women, Fetal distress had resulted into mortality for $4(14.3 \%)$ babies. $6(21.4 \%)$ succumbed to morbidity due to Cord Compression, 2 (7.14\%) due to Necrotizing enterocolitis, $3(10.7 \%)$ due to Hypoxia and sepsis had been the cause of death for 8 (28.5\%) newly born babies. 


\section{DISCUSSION}

Premature rupture of membranes (PROM) is defined as rupture of the amniotic sac membranes before labour onset at 37 weeks of gestation or later. It constitutes a significant problem in obstetrics. It is termed prolonged rupture of membrane if it persists for more than 24 hours to onset of labour (Jazayeri). ${ }^{11}$ The identification of pathologic microorganisms in human vaginal flora soon after membrane rupture provides support for the concept that bacterial infection may have a role in the pathogenesis of pPROM (McDonald et al). ${ }^{12}$

Premature rupture of the amniotic sac membranes enclosing the fetus is, as yet, a not fully understood process, but may related to the mechanical properties of those membranes (Wittenberg). ${ }^{13}$ Umbilical cord blood cytokine values are higher than maternal levels, suggesting significant fetal/placental contribution. Maternal and umbilical cord cytokine levels are not adequately predictive to be used clinically (Mercer et al. ${ }^{14}$ )

Premature rupture of membranes occurs between 5 and $15 \%$ of pregnancies, of these, $10 \%$ occurs at term and preterm 2 to $3.5 \%$ (Hernández et al). ${ }^{15}$ Previable or Preterm (less than 24 weeks) premature rupture of membranes (pPROM) complicates about 1 in every thousand births and is responsible forl substantial perinatal mortality (Margato et al). ${ }^{16}$ It is the leading identifiable cause of premature birth and accounts for approximately $18 \%$ to $20 \%$ of perinatal deaths in the United States (Caughey). ${ }^{17}$

Clinical factors associated with preterm PROM include low socioeconomic status, low body massindex, tobacco use, preterm labour history, urinary tract infection, vaginal bleeding at any time in pregnancy, cerclage, and amniocentesis. Fetoscopy may carry a risk of iatrogenic pPROM, although this depends on the experience of the obstetrician (Gratacós). ${ }^{18}$

This study was conducted in the department of obstetrics and Gynecology, katihar medical college hospital with 60 pregnant mothers attended and admitted through OPD and Emergency with complaining leaking per vagina.

The demographic profile of PPROM patients in our study such as below age of 24 year, and single gravidity was similar to those reported in other areas (Shehlar, Akter et al). ${ }^{19,20}$ Noor et al in an observational study found that pPROM was more frequent among women belonging to low socioeconomic class, and those with no or low education. ${ }^{19}$ Similar findings were also reported by Polzin and Brady who asserted that the rates of pPROM negatively correlated with the socioeconomic level. Meanwhile, Ortiz et al could not find any relation of statistical significance between women's socio-economic variables and the risk of having PROM. ${ }^{21}$
It was noted in a study done by Mead et al and Garite et al that about $50 \%$ of PPROM between 28 and 34 weeks of gestation age tend to go into labour within 24 hours. ${ }^{22,23}$ This was different in our study were $62 \%$ of patients between 28-34 weeks of gestation age went into spontaneous labour after 72 hours. This increase maybe was due to the antibiotics given that led to an increase in the latency period in our study. This increase in latency period was also noted in a study done by Mercer et al ${ }^{\mathrm{i}}$. However, in contradiction with this current study finding regarding women's age, Berkowitz et al in their study about the risk factors for preterm birth found that mothers 30 years age or older had a significantly increase risk for pPROM. $^{24}$ On the same line, a large population-based retrospective cohort study of the risks of maternal morbidity and adverse outcomes showed that increasing maternal age was associated with a significantly higher risk of pPROM after adjusting for maternal race, parity, diabetes, chronic hypertension and smoking status (Lucke and Brown). ${ }^{25}$ Similarly Ziadeh in a large study conducted in Jordan found that women delivering their first child at age 35 years or older were at increased risk of pPROM compared with women aged 20-29 years of age. Ferguson et al also had a similar finding regarding maternal age. ${ }^{26,27}$

In our study about $3.3 \%$ patients were running fever of $38^{\circ} \mathrm{C}$ or more at the time of admission. All patients were given broad spectrum antibiotics. Intrapartum fever accompanied by two or more additional signs including foetal tachycardia, uterine tenderness, foul smelling vaginal discharge or maternal leukocytosis occurs in $1.0 \%$ to $3.8 \%$ of parturient and is associated with neonatal Group B Streptococcal (GBS) attack rates from $6 \%$ to $20 \%$ cases. $^{2}$ Reports of three meta-analysis of randomized blind studies showed that initiating systemic antibiotics after occurrence of PPROM had two major effects: first, increased latency (time until delivery) and second, reduced occurrence of neonatal sepsis, interventricular hemorrhage and perinatal mortality and chorioamnionitis.

Caesarean section rate in this study was $35 \%$ which is similar to that reported in the study from Punjab. It is low as compared to the study by Charles $\mathrm{P} \mathrm{J}$ et al in which the incidence of caesarean section was $58.7 \% .^{28}$ In our study caesarean section was mostly performed for fetal distress and malpresentation, while in the above-mentioned study caesarean section before labour was the most frequent mode of delivery. This is because of cultural differences in this part of the world where large families and vaginal deliveries at home are preferable.

In our study, $6.67 \%$ cases had previous preterm deliveries. This incidence is lower than reported by Tahir et al (14.7\%) and Charles P J et al (14.3\%). ${ }^{28,29}$ Thus risk scoring strategies can be developed on the basis of prior preterm birth. However the use of the scoring systems has resulted not in significant reductions in preterm births but 
rather in an increased use of intervention with unproved effectiveness. ${ }^{3}$

The number of low birth weight babies in this study was $61.6 \%$ as compared to $62.3 \%$ by Shehlar et al and it is very high as compared to United States and California birth cohorts in which the prevalence of prematurity was $10.3 \%{ }^{4,19}$ This large number of low birth weight babies puts great burden on the neonatal intensive care facilities. Number of babies with low APGAR score who required advanced resuscitation were also high. Perinatal mortality in this study was $21.7 \%$ (13/60 births), which is lower than reported by Tahir et al but higher than reported by Multer et al (9.3\%) and by Charles P J et al (3\% at 28-31 weeks and $0.41 \%$ at $32-33$ weeks). ${ }^{28,29}$ Neonatal morbidity and mortality are directly related to latent period and PROM delivery interval. Perinatal morbidity was mainly due to cord compression, RDS (Respiratory Distress Syndrome), sepsis, very low birth weight and mortality was mainly due to sepsis, RDS and birth asphyxia as similar to study done by Kadikar GK et al. ${ }^{30}$

In our study, the result revealed that the poor fetal outcome in women with preterm premature rupture of membranes was associated with a gestation age of less than 34 weeks and an extremely low birth weight. As such, more efforts have to be made to improve our neonatal intensive care unit so that they become better equipped to deal with such kind of complications to improve the outcomes.

\section{CONCLUSION}

Mostly mothers were $<24$ year age with mean age $25.73 \pm 5$.1years. In early age pregnancy of mother major cause of low birth weight babies. Preterm prelabour of the fetal membranes contributes to one-third of all preterm births, and is the leading identifiable cause of prematurity and its sequels. Additionally, the probability of positive culture is higher with pPROM, particularly with sterile infection. Diagnosis of PPROM should be via speculum examination; digital vaginal examination should be avoided. PPROM is one of the important causes of preterm birth that can result in high perinatal morbidity and mortality along with maternal morbidity. Routine administration of oral erythromycin to women with PPROM will significantly increase the latency period and improve neonatal respiratory morbidity. Administration of antenatal corticosteroids to women presenting with PPROM improves neonatal outcomes without increasing the risk of infection. There is no evidence regarding the safety or benefit of tocolysis in women with PPROM. Conservative management to prolong gestation should be performed in the absence of evidence of infection. There is currently no evidence regarding the risks and benefits of prolongation of gestation beyond 34 weeks gestation. Looking after a premature infant puts immense burden on the economic and health care resources of the country; therefore risk scoring strategies involving the demographic variables along with previous history of preterm deliveries should be developed to identify high risk cases and treating them prior to rupture of membranes.

Funding: No funding sources Conflict of interest: None declared

Ethical approval: The study was approved by the Institutional Ethics Committee

\section{REFERENCES}

1. Kitzimiller JL. Preterm premature rupture of membranes. In Fuchs Fand Stubblefield P.G(eds):Preterm birth: causes, prevention and management. $1^{\text {st }}$ edition. MacMillan; 1984:298-322.

2. Allen RS. The epidemiology of premature rupture of membranes.Clin Obstet Gynaec. 1991;34:685-93.

3. Kanayama N, Terao T, Kawashima Y, Horiuchi K, Fujimoto D. Collagen types in normaland prematurely ruptured amniotic membranes. Am J Obstet Gynecol.1985;153(8):899-903.

4. Artal R, Sokol RJ, Neuman M, Burstein AH, Stojkov J. The mechanical properties ofprematurely and nonprematurely ruptured membranes. Am J Obstet Gynecol. 1976;125(5):655-9.

5. Skinner SJ, Campos GA, Liggins GC. Collagen content of human amniotic membranes:effect of gestation length and premature rupture. Obstet Gynecol. 1981;57(4):487-9.

6. McGregor JA, French JI, Lawellin D, Franco-Buff A, Smith C, Todd JK. Bacterial protease-induced reduction of chorioamniotic membrane strength and elasticity. Obstet Gynecol. 1987;69(2):167-74.

7. Parry S, Strauss JF. Mechanism of disease: premature rupture of the fetal membranes. N Engl J Med. 1998;338:663-70.

8. Mercer BM, Arheart KL. Antimicrobial therapy in expectant management of preterm premature rupture of the membranes. Lancet. 1995;346(8985):1271-9.

9. Harding JE, Pang J, Knight DB, Liggins GC. Do antenatal corticosteroids help in thesetting of preterm rupture of membranes? Am J Obstet Gynecol. 2001;184:131-9.

10. Joseph KS, Kramer MS, Marcoux S, Ohlsson A, Wen SW, Allen et al. Determinants ofpreterm birth rates in Canada from 1981 through 1983 and from 1992 through 1994. N Engl J Med. 1998;339:1434-9.

11. Jazayeri A. Medical Director of Perinatal Services, Aspirus Hospital; Consulting Staff and Owner, Women's Specialty Care. Premature Rupture of Membranes. Available at:http://emedicine.medscape.com/article/261137overview.

12. McDonald HM, O'Loughlin JA, Jolley P, Vigneswaran R, McDonald PJ. Vaginal infection and preterm labour. $\mathrm{Br} \mathrm{J}$ Obstet Gynaecol. 1991;98(5):427-35.

13. Wittenberg GF. Elastic properties and yield stress of fetal membranes Conf Proc IEEE Eng Med Biol Soc. 2011;2011:2123-6. 
14. Mercer B, Milluzzi C and Collin M. Periviable birth at 20 to 26 weeks of gestation: proximate causes, previous obstetric history and recurrence risk. Am J Obstet Gynecol. 2005;193(3.2):1175-80.

15. Hernández y Ballinas AC, López Farán JA, Gámez Guevara C. Comparison of maternal and perinatal outcomes in the conservative treatment preterm premature membrane rupture between the use of erythromycin and clindamycin. Ginecol Obstet Mex. 2011;79(7):403-10.

16. Margato MF, Martins GL, Passini Júnior R, Nomura ML. Previable preterm rupture of membranes: gestational and neonatal outcomes. Arch Gynecol Obstet. 2011.

17. Caughey A. Contemporary diagnosis and management of preterm premature rupture of membranes. Obstetric Gynecology. 2008;1(1):1122.

18. Gratacós E. Fetoscopy and Risk of Iatrogenic Preterm Premature Rupture of Membranes: Not as High as It May Seem (in Experienced Hands). Fetal Diagn Ther. 2012;31(1):10-1.

19. Noor S, Fawwad A, Shahzad H, Sullama R, Bashir R. Foetomaternal Outcome in patients with or without PROM. Journal Ayur Med.

20. Akhter S, Rasihd M, Akter R. Journal of Bangladesh College of Physician Singoel. 2010;28:1.

21. Ortiz FM, Soto YG, del Refugio VG, Beltran AG, Castro EQ. Social-economic and obstetric factors associated to premature rupture of membranes. Ginecol Obstet Mex. 2008;76(8):468-75.

22. Mead PB. Management of the patient with premature rupture of membranes. Clinics Perinatol. 1980;7:243355.
23. Garite TJ, Freeman RK, Dinzey EM, Braly P. Am J Obstet Gynecol. 1981;141:508.

24. Berkowitz G, Blackmore-prince C, Lapinski R, Savitz D. Risk factors for preterm birth. Epidemiology. 2008;9:279-85.

25. Brown MA, Lindheimer MD, de Swiet M, Van Assche A, Moutquin JM. The classification and diagnosis of the hypertensive disorders of pregnancy: statement from the International Society for the Study of Hypertension in Pregnancy (ISSHP). Hypertens Pregnancy. 2001;20:IX-XIV.

26. Ziadeh S. Maternal and prenatal outcome in nulliparous women aged 35 and older. Gynecology Obstetric Invest. 2002;54(1):6-10.

27. Ferguson S, Salenieks M, Windrim R, Walker M. pPROM. Nutrition and socioeconomic factors. Obstetric Gynecology. 2008;100(6):1250-6.

28. Charles PJ, Muriel R, Charles PJ, Reni E, Olivienc, Pascal G, et al. A prospective population bared study of 598 cams of PROM, description, management and mortality. Eur J Obstet Gynecol Reprod Boil. 2005;121:164-70.

29. Tahir S, Aleem M, Aziz K. Incidence of outcome of PROM. Pak T Med Sci. 2002;18(1):26-32.

30. Kadikar GK. A study of feto-maternal outcome in cases of premature rupture of membrane. IJSR. $2014 ; 3: 3$

Cite this article as: Khan S, Khan AA. Study on preterm pre mature rupture of membrane with special reference to maternal and its fetal outcome. Int J Reprod Contracept Obstet Gynecol 2016;5:2768-74. 